\title{
Study on the Interactive Packaging Design Based on Emotional Experience
}

\author{
Mi Yang \\ Binzhou University \\ Binzhou, China 256600
}

\begin{abstract}
Objective to study the application of interactive design in product packaging, interactive packaging design method based on emotional experience, Guide the practice of packaging design. Method Combined with the actual design case study, it describes the three different types and characteristics of emotional experience in packaging design, and summarizes the design principle of interactive packaging based on the emotional experience from four aspects. The application of interactive design and innovation in packaging design can give users a better emotional experience, it will increase the added value of the product and brand recognition, and provide the theoretical basis for the packaging designers.
\end{abstract}

Keywords-emotional experience; interactive; packaging design; design method; design principle

\section{INTRODUCTION}

With the development of economy and change of consuming pattern, our country has entered the age of "Experience Economy". The consumers are no longer satisfied with basic demand on material level and start to require products to satisfy their emotional and psychological need [1]. On the background of experience design and emotional design theory, interactive packaging design aimed at touching users' emotion and satisfying psychological need emerges at the right moment. Interactive packaging design can motivate the emotional experience generated from its interaction with users, and make people resonate with it deeply and gain abundant aesthetic experience.

\section{THREE LEVELS OF USERS' EMOTIONAL EXPERIENCE}

The emotional experience refers to the joyful experience which users gain in the process of appreciating and using the product. A cognitive psychologist Donald Arthur Norman (1935.12.25-) divides emotional experience into three levels: instinct level, behavioral level and reflective level "Fig. 1". The instinct level is the user's direct emotional reaction and emotional experience brought by appearance and style of the product sensually, namely the sensory stimuli to the user brought by the shape, color and quality of the product; the behavioral level mainly reflects on all the feelings and experience brought when the user uses the product's function, including the user using it to study or solve the existing

Fund project: National University Students' Innovation Plan Training Project of Binzhou University, Project Number: 201510449030; scientific research fund project of youth talent's innovation project of Binzhou University, Project Number: BZXYQNRW200710; Teaching Research Project of Binzhou University, Project Number: BYJYWZ201334. problem with certain skill, and the psychological and emotional satisfaction such as sense of joy and achievement during this dynamic process; the reflective level is the highest level of the user's emotional experience, which is the feeling and thought of the user after using the product, the symbolic implication endowed to the product form by the designer via various design methods, and the high-quality and high-grade individual emotional experience gained via understanding the symbolic implication of the product form. Donald Arthur Norman analyzes the diversity of human's emotions, reveals the subtle relationship between emotional experience and product. The emotional experience of instinct level, behavioral level and reflective level keeps circulating and progressing, influencing and permeating each other, the design of the reflective level reacts upon the instinct and behavioral levels, inspiring the designer's innovative thinking and practice again, and the designed product is used and experienced by the user again, forming an interaction among the designer, product and user[2]. The theory of three levels of emotional experience raised by Donald Arthur Norman for product design also applies to the field of packaging design, where the designer conducts interactive packaging design from three levels of emotional experience, which can enable consumers to gain more various and deeper emotional experience.

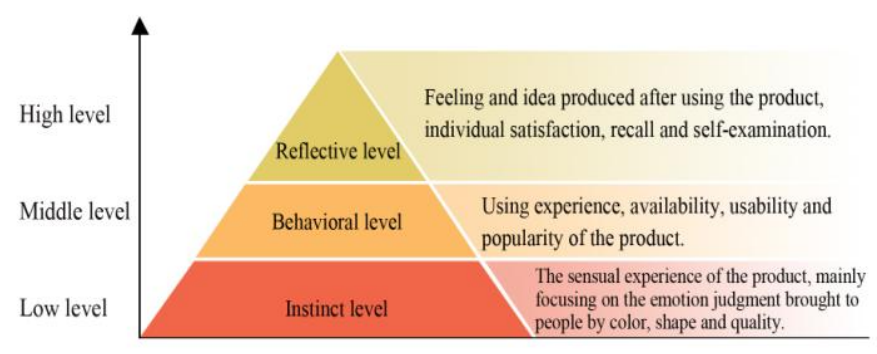

Fig. 1. Three levels of user emotional experience

\section{MEANING OF INTERACTIVE PACKAGING DESIGN}

The interactive packaging design is a design form and process which takes marketing mode of emotional experience as principle, applies interact idea to product package[3]. The emotional experience is a pleasant experience during interaction of the product packaging, focusing on availability and usability of the product and bringing users happy experience. The human-centered design of interactive design stresses the interaction between human and things and between 
human and human. The combination of interactive design idea and packaging design is interactive packaging design. Compared to traditional packaging design, the interactive packaging design is based on the research of people's behavioral feature and psychological need, paying attention to the interaction between user and package, and the continuous and foreseeable experience during this process, evaluating the quality of the design from aspects of the availability, effectiveness and pleasure of the package. In packaging design, the designer shall fuse the user's emotional experience and interactive design idea, rationally foresee the behavior and detail during interaction, center on user's emotional experience, and apart from conveying the basic information of the product, the designer shall also artistically express the package and endow it with more emotional value. Emotional product package needs to take the method of interactive design to let people gain higher level of emotional experience. Good interactive design calls for emotional experience to satisfy the demand of users to shape their own social image.

\section{The PACKAgING Design Method of EMOTIONAL EXPERIENCE INTERACTIVE}

\section{A. The Design Method Basic Instinct Emotional Level}

The emotional experience on instinct level is mainly the reaction motivated by instinct auditory, visual, tactile, taste and smell sense of the user during package interaction [4]. It is the most direct and strongest starting point of emotional experience, the first response and impression of user to the product package, and "visual impact" that people often talk about belongs to typical emotional experience on instinct level. The packaging design based on emotional experience on instinct level has to conform to the rule of formal beauty, associate and image, take proper art expressive method, and quickly attract users via strong sensory stimuli brought by design elements such as abundant color, exquisite composition, elegant shape, unique material and special style, satisfy users' aesthetic demand of package and product's perceptual features, bring pleasant emotional experience to the user and stimulate their buying inclination.

Nowadays, the hair accessory products are severely homogenized, leading to fierce market competition. As a brand new Thai hair accessory brand, St. Stephen has to own special and distinctive brand image to stand out in competition. Somchana Kangwarnjit, Executive Creative Director of Prompt Design perfectly completes this mission. St. Stephen mainly produces high-quality bobby pin and rubber band, whose function is to create abundant hair styles. St. Stephen hair accessory package designed by Somchana Kangwarnjit combines the product and package "Fig. 2". Serialize design forms simple but strong formal beauty, strengthen the effectiveness of information transmission of the product: there is a nifty expression of a beautiful woman on the package who has no hair, and products like tuck comb forms various beautiful hair styles, clearly and effectively explaining the product function and feature-it can change various hair styles to fit consumers with different demands. Somchana Kangwarnjit connects product feature to aesthetic taste, gaining excellent display effect, helping user understand features of different products, increasing sales volume of products, and this design got 2012 Pentawards Silver Award for its creativity.
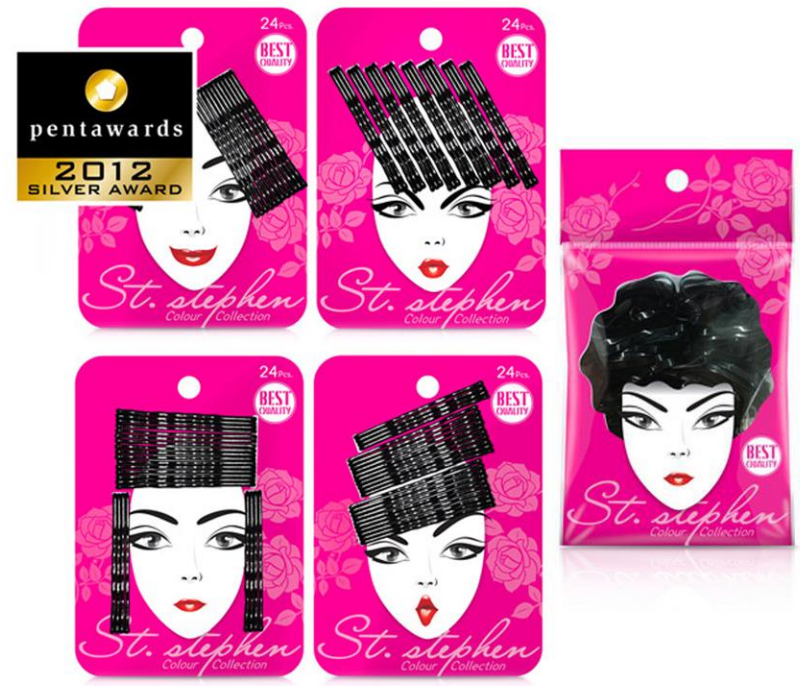

Fig. 2. St.Stephen brand hair accessories (the figure is from official website of Prompt Design)

It's very important for the packaging design to pay attention to emotional experience on instinct level, but it has to avoid paying attention to hollow appearance beauty only and neglecting the connotation value of the product, which can not be accepted by general users. Good design based on emotional experience on instinct level is not low and mediocre, but must contain certain connotation and depth. While packaging design pursues aesthetic value, it also has to combine the design based on emotional experience on other two levels, and considers the comprehensive feelings of users all the time, only in this way can package design get innovative development [5].

\section{B. The Design Method Based on Emotion on Behavioral Level}

The emotional experience on behavioral level is higher than that on instinct level, which pays attention to the feelings of users when they use the package and centers on functionwhether it's convenient to open, whether it's safe and efficient to use and whether it can bring pleasure and sense of satisfaction to users when people use the product. The emotional experience on behavioral level is not only gained by effectively realizing the function of the product package, what's more important is that it can make users join in interesting interaction, relieve their fatigue mind and body. Good usability is the key of emotional experience on behavioral level. Design shall center on users, conform to humanized design principle, understand and satisfy the users' demand, make the function, structure and shape of the product get accepted by the user, enable users to enjoy pleasure when they use the product and bring them active emotional experience.

To aim at targeted users, the design not only has to work hard on the pattern color of the package, but also has to create 
perfect outer shape and inner structure of the package. For example, kids are naturally lively and active with abundant emotions, and they like things with affinity and interest. They always notice and like products with special appearance and original shape [6]. Spanish EROSKI children's oatmeal makes the normal package which would be throw up more interesting "Fig. 3". The designer transfer animals like elephant and giraffe which are popular among children into optimistic cartoon image via aesthetic treatment and apply it to aesthetic treatment of children's food, satisfying children's pleasure of vivid color and abundant patterns visually at first. What's more, the designer puts much effort in the reverse side of the package and prints the method of paper folding of corresponding animals, making food package a DIY toy, adding functionality to food package, letting children taste delicacy while feeling motivation of intelligence and potential when they play paper folding. The diversified package with interest endows EROSKI brand with more appetency and infection. This design won 2014 Vertex best display award, gold award and 2014 Pentawards silver award.

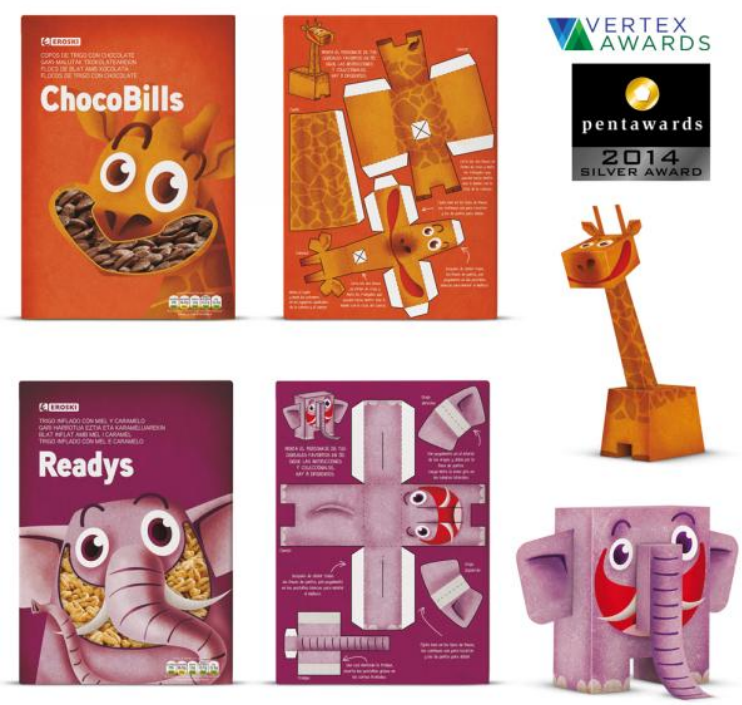

Fig. 3. EROSKI children's cereals package design (the figure is from the official website of Pentawards)

\section{The Design Method Based on Emotion on Reflective Level}

After emotional experience on instinct level and behavioral level, people also expect to get interesting exploration and satisfaction of realizing self-potential and talent when using the product [7]. The emotional experience on reflective level is the high level of emotional experience for users, depending on high-level thinking activity of the user, a conscious experience of product's information, sign and environment, a visual element through which people watch product package, understand the inner structure, function and quality of the product, and then understand the social image of the product. The deeper layer of reaction generated by cultural background and implication represented by social product decides the users' general impression on the product. With the improvement of users' demand to social intercourse, selfesteem, cognition and self-actualization, as a social medium and tool, the product conveys the culture, interest, value and taste of the owner, motivates people to actively evaluate emotion. The designer shall apply association, imagination, exaggeration, humor and metaphor based on different design objective, endow the product with abundant cultural connotation, and express special cultural image with innovative form and satisfy the deep-layer psychological and emotional need of users.

The packaging design based on emotional experience on reflective level always exceeds people's simple demand and wish of function, and some even becomes a type of new product independently, not only as a shell to protect and hold the product. For example, people may think hat the plastic or glass honey pot in the current market take up space and would throw it away after eating the honey up "Fig. 4". It is the Stanley Honey pot which has won many awards. The designer innovatively fuses the idea of green and environmental protection into packaging design to enable it to recycle. Stanley Honey is packaged in a fashionable stean with cork. The shape of the stean is like a flowerpot very much, and after we eat the honey up we use the stran to plant flowers. The designer sets a smart detail, the cork of the steam can reverse to serve as the cork base of the flowerpot. This design encourages people to recycle packages to plant flower, attracting honey and serving for future honey production.
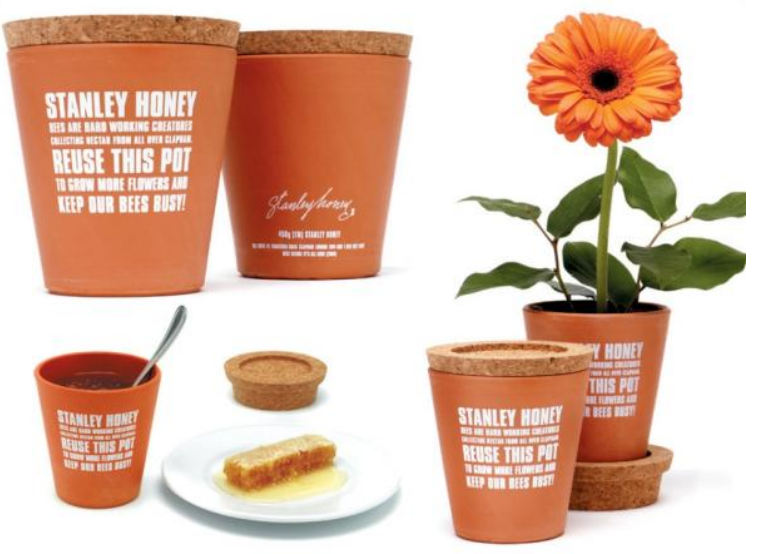

Fig. 4. Stanley Honey Pots (the figure is from the official website of welovead)

The interactive packaging design can attract consumers to participate in interactive experience, enable them to set up good emotional connection, and fully satisfy the individual and multi-layered emotional demand of modern people. The designer needs to express close care to people from three different cognitive levels, instinct, behavioral and reflective, consider from the difference and multidimension of the consumer psychology, research life style and values of different types of people, improve the identifiability and awareness of product and expand the market and add value to it via design of multi-layered emotional experience and multicycled interaction information feedback. 


\section{PRINCIPLE OF INTERACTIVE PACKAGING DESIGN BASED ON EMOTIONAL EXPERIENCE}

\section{A. Principle of Identifiability}

It requires interactive packaging design to fully consider users' cognitive features, conduct detailed design improvement or change via color, word, texture and shape, present in expressive form familiar to users, make the package enable users to understand product's information and function in a short time, make the interaction process easier, more effective and more interesting, realize the adaptation of interaction and users' life, and harmony between using situation and users' behavior.

\section{B. Principle of Availability}

The availability of interactive packaging design mainly stresses the balance among user, behavior and technology. The interactive packaging design has to conform to the positioning of target user of the product, and its availability is based on the usability of the basic function of package. The usage of the package shall be easy to learn, understand and use, and convenient for most people [9], whose major requests include: it's easy for users on different levels to learn to open package or use the product, it's convenient to open the package for users, the error rate is low and efficiency is high when using the product function, and the safety is guaranteed.

\section{Principle of Usability}

When conducing interactive packaging design, it shall take the demand of various backgrounds and people into consideration, offer wide multi-layered interactive technology form for users in different condition and physical ability to choose, can offer proper package size and space to get close to, use and store package, making interaction between human and package more convenient and harmonious[9], and there is no need to consider the height, posture, or moving ability, such as individual orientation, skill disorder and operation environment.

\section{Principle of Popularity}

It requires designers to aim at satisfaction, pleasure and interactive experience of the users, consider aspects of behavioral and emotional communication between user and product package, let user feel the material and spiritual value during appreciating, choosing, thinking, buying and using the product [10]. Lively, original and interesting interactive packaging design generally has special opening approach an operation interest, which can enable users to be willing to join in experience, feel the pleasure and interest which can not be brought by traditional package, and enable users not only to get the using value of the product itself and gain emotional interest and satisfaction.

\section{CONCLUSION}

Consumers nowadays are longer satisfied with simple function of protecting product of the package, and they show special preference to package which can DIY or even be recycled with special creativity and interest, hope to get interactive emotional experience on a deeper level[11]. Designers have to follow the trend of era development, insist on "people first", fully take use of various new material, new technology and design concept, conduct emotional design from instinct, behavioral and reflective levels, satisfy their multilevel, multi-aspect and three-dimensional functional and emotional demand with product with strong identifiability, availability, usability and popularity, change and guide the life of consumers with innovative design.

\section{REFERENCES}

[1] Li Ying.Research of Packaging Continuity Experience Design:Take Orion Xylitol “Lilichu” Gum Packing as an Example[J].Art \& Design, 2013(6):100-101

[2] ZHANG Cui.The Study on the Packaging Design with Basic of Emotion Experiencement[D].Wuhan:Wuhan University of Technology,2009.

[3] Zhang Mengmeng.The Applied Study of Interactive Ideas in Packaging Designs[D].Kaifeng:Henan University, 2013.

[4] Zheng Xiaona.New Forms of Modern Packaging Design Development and Application Research.[D].Tianjin:Tianjin University of Technology, 2012.

[5] LI Yan, WEI Yang-yang.Exploration of Product Packaging Design Based on User Experience[J].Art and Design, 2015 (3): :42-44.

[6] JIN Gui-fang, LANG Ting-ting.Children' s Toy Packaging Design Based on Emotional Experience and Rational Cognition[J].Packaging Engineering, 2015, 36 (14):106-109.

[7] LI Duo.Emotion • Packaging • Design[J].China Packaging, 2013 (9) :55-57.

[8] WANG Xuan, YAO Jun, NIU Wei-peng, et al.The Method of Interactive Product Design Based on Affordance[J].Packaging Engineering, 2015, 36 (12):99-103.

[9] ZHANG Yunfan, WANG Anxia , LI Shiguo.Application of Interactive Design Concept in Packaging Design[J].China Packaging, 2007(6): 31-32.

[10] HAO Xiu-mei.Exploration of Experience-type Packaging Design Based on Emotional Expression[J].Packaging Engineering, 2014, 35(14):59.

[11] LU Yao,WEI Zhang.Application of Interactive Design Theory in Packaging Design[J].Modern Decoration(Theory), 2013 (11) :23-24. 